\title{
Problems of introducing a system of paid water use in irrigated agriculture in water-deficient regions of Russia (on the example of the Rostov region)
}

\author{
Grigory Kharitonov ${ }^{1, *}$ \\ ${ }^{1}$ Don State Technical University, Gagarina sq. 1, Rostov-on-Don, 344003, Russia
}

\begin{abstract}
In the face of climate change, regulation of water use is essential. On the example of the Rostov region, the necessity of introducing paid water for agricultural lands was considered. Rostov region is one of the largest producers of agricultural products, including wheat and sunflower. At the same time, this territory belongs to arid territories and needs irrigation of agricultural land. The Lower Don basin on the territory of the Rostov region includes the territory from the Tsimlyansk reservoir to the river mouth. The quality of water resources and river runoff of large waterways in the Don region is largely determined by small rivers, whose environmental problems are also associated with a high anthropogenic load, indicating intense economic activity. The article discusses the possibilities of using the system of payment for water use for agriculture. It is shown that the introduction of a system of tariffs for irrigation water, as well as the modernization of existing legal norms, will reduce the anthropogenic load on the ecosystem. The systemic regulation of water use should ultimately lead to the modernization of the system of irrigation canals and the cleaning of small rivers in the region.
\end{abstract}

\section{Introduction}

In the conditions of the dry steppe zone, an important component of the natural environment is the water resource potential. In the last few years, the main waterway of the Rostov region, the Don River, has been shallowing, which forces us to look for mechanisms to regulate the consumption of water resources.

Irrigation provides more than $40 \%$ of world agricultural production, and since 1960, it has accounted for more than $50 \%$ of production growth [1].

Agriculture is the main user of the world's limited freshwater resources [2]. In the Russian Federation, water withdrawal for irrigation of irrigated lands accounts for up to a quarter of the total consumption of water resources by the economy. At the same time, the efficiency of irrigation water use in our country is much lower than in the EU countries and the USA.

*Corresponding author: haritonov.gr@mail.ru 
The lack of real incentives to rationalize water use has led to extremely low efficiency in the use of water resources in agriculture in Russia. One of the main reasons for the low efficiency of water resources use in irrigated agriculture is the lack of payment for the use of irrigation water by the enterprises of the reclamation complex [2-4].

One of the main directions of increasing the ecological and economic efficiency of the use of water resources in irrigated agriculture is the transition of this branch of management to paid water use. This approach will contribute to the resource-saving development of enterprises of the reclamation complex and reduce the specific water intensity of agricultural production on irrigated land. Payment for the use of water resources will create a basis for the formation of market-based environmentally friendly regulators. This will contribute to the improvement of economic instruments for regulating the use of natural resources in irrigated agriculture.

The main goal of this study is to find an answer to this question: will the introduction of payment for water use for agriculture have a positive impact on the state of water resources in the region? The effectiveness of the impact of paid water use was determined based on the analysis of two factors. First, the conditions for the functioning of the regional reclamation complex were taken into account. Secondly, the proposed approach was based on the analysis of the organizational and legal forms of the subjects of irrigated agriculture.

\section{Materials and methods}

\subsection{Subject of study}

To develop a water resources management system, it is necessary to take into account the features of the formation and use, as well as the current state of water resources. The Lower Don basin in the Rostov region includes the territory from the Tsimlyansk reservoir to the river mouth, including the main tributaries of the Seversky Donets and Western Manych. Large rivers flow through the region: Don, Khoper, Seversky Donets, Medveditsa, as well as several dozen small and medium rivers. There are several thousand irrigation canals in the Lower Don (distribution, inter-farm, on-farm and drainage) [5].

Given the arid climate of the region, water resources should be recognized as one of the main limiting factors of the socio-economic development of the region. A strong indirect anthropogenic impact on water bodies in the catchment area is associated with the settlement of the territory and the economic activities of residents [6]. The main consumers of water resources in the region are agriculture, industry, and the household consumption system. The main areas of water use are irrigation system, irrigation of pastures, aquaculture and commercial pond fish farming [7]. The most water-intensive sector of the economy is the industry, which accounted for $>58 \%$ of total water consumption in 2018 [5]. Another natural consumer of water is the ecosystem of the Sea of Azov, and, above all, the Taganrog Bay. However, this fact was declarative in the distribution of water resources between the above-mentioned users [8].

The main source of water resources in the Rostov region is the inflow of water from the Tsimlyansk hydroelectric complex. However, its design did not take into account the cyclical nature of the climate, which causes the alternation of long dry and wet periods. The Azov and Lower Don regions are characterized by dry periods with cycles lasting up to 10 years. In the XXI century, the trend of climatic iridization and reduction of water discharges down the river has intensified. Don through the Tsimlyansk hydroelectric complex. The incoming part of the water balance of the Tsimlyansk reservoir is $19,764 \mathrm{mln}$ $\mathrm{m}^{3} /$ year. It is dominated by tributaries along the river Don, which amount to 17600 million $\mathrm{m}^{3} /$ year. The second position is occupied by precipitation, which is 1100 million $\mathrm{m}^{3} /$ year. 
In the expenditure part, the volume of runoff through the turbines of the hydroelectric power station was at the level of 12,800 million $\mathrm{m}^{3} /$ year, and the volume of water for the needs of industrial and agricultural enterprises was 2301 million $\mathrm{m}^{3} /$ year [8]. In 2015, the flood volume in the Tsimlyansk reservoir did not exceed $4 \mathrm{~km}^{3}$ (35\% of the norm), and the maximum discharge was $790 \mathrm{~m}^{3} / \mathrm{s}$ (i.e. $1 / 4$ of the norm). However, starting from 2016, an increase in the maximum and average monthly water discharges into the downstream of the reservoir has been observed against the background of an increase in the level of the upstream [8].

Analysis of the provision of the population and economy in the basin with water resources at the current level showed that in general, in the Don basin, $4.1 \mathrm{~km} 3$ are irretrievably withdrawn per year (excluding the basins of the Seversky Donets and Western Manych rivers), and the value of the permissible irreversible runoff withdrawal is $3.9 \mathrm{~km}$ $[6,9]$. Some researchers note that economic activity on the territory of the Rostov region in the Lower Don basin for a long period has been developing without taking into account the ecological limitations determined by the assimilative capacity of river ecosystems and the Sea of Azov as a trailing water body. This has led to exaggerated amounts of withdrawal and irrevocable consumption of surface water, a decrease in the volume and quality characteristics of freshwater runoff, and an increase in soil erosion. For the region, there is a tense water management situation associated with the almost complete depletion of its water resources for additional use.

A further increase in irreversible runoff withdrawal in the basin is unacceptable without compensation from external sources [6]. At the same time, the main purpose of the operation of the Lower Don system is to ensure a sufficient volume, adequate quality of water resources and preserve the commercial fish fauna [8]. In recent decades, undesirable changes in natural and climatic conditions have taken place. First of all, the volume of river flow in the Don basin is decreasing. As a result, a complex of negative consequences for the ecosystem and the national economy has arisen, such dangerous hydrological and geographical phenomena as low water, extreme surges and surges in the delta of the river [10]. Don, salinization of the Taganrog Bay (up to 2-8 \%o), oxygen deficiency, rapid "blooming" of microalgae [8]. It is necessary to highlight the problems of the Tsimlyansk reservoir, practically exhausted by 2002: coastal abrasion, silting, shallowing, the extreme development of microalgae. Currently, the reservoir hurts the entire system of the Lower Don [8].

In the region, environmental requirements have been established in terms of the withdrawal of water resources for each water management site, and standards for permissible irretrievable drainage have been adopted. The assessment of compliance with the established environmental requirements is carried out by comparing the approved standard of permissible irrevocable withdrawal of runoff and the actual irretrievable withdrawal of runoff at water management sites [5].

The region has established environmental requirements in terms of the withdrawal of water resources for each water management site and adopted standards for permissible irrevocable withdrawal of runoff. The assessment of compliance with the established environmental requirements is carried out by comparing the approved standard of permissible irrevocable withdrawal of runoff and the actual irretrievable withdrawal of runoff at water management sites [5].

The quality of water resources and river runoff of large waterways in the Azov-Don region is largely determined by small rivers, the environmental problems of which are also associated with high anthropogenic load, which indicates intense economic activity and the use of water resources for watering, water supply and disposal in fish, agriculture, industrial and other farms. Livestock complexes, industrial enterprises, and irrigation systems pollute the rivers of the basin. Water quality is influenced by the unregulated washout of pollutants 
from urbanized and agricultural areas. The intense anthropogenic load led to such negative processes as siltation of channels, loss of drainage capacity by watercourses, floodplain swamping, rise in the level of groundwater, etc. [5].

To develop effective management decisions in the field of irrigated agriculture, it is necessary to take into account the type and volume of agricultural products produced in the region. There was a significant increase in the number of grain crops produced in the Rostov region, according to the Federal State Statistics Service of the Russian Federation. For example, the production (gross yield) of wheat increased from 61.0 million tons in 2010 to 121.2 million tons in 2019. At the same time, the volume of wheat exports increased to $32 \%$ of the total produced amount. The Rostov Region is one of the participants in the global agricultural market.

\subsection{Mechanisms of state regulation of water policy}

Several legal regulations regulate the use of water resources. It should be noted that the water accounting system is not transparent, especially for agricultural land. By the current legislation of the Russian Federation (the Civil Code, the Water Code of the Russian Federation of 03.06.2006, No. 74-FZ, the Tax Code, the Water Strategy of the Russian Federation for the period until 2020, the Federal Law of 21.11.1996, No. 129- Federal Law "On Accounting", Federal Law dated January 10, 1996, No. 4-FZ (as amended on December 30, 2008) "On Land Reclamation", Federal Law dated January 12, 1996, No. 7FZ " On non-commercial organizations ") and approved by the Charters of melioration institutions and their branches.

\section{Results and Discussion}

\subsection{Analysis of the water consumption regulation system in the Rostov region}

According to the study [7], the consumption of water resources for irrigation and irrigation systems has decreased three times over the past 27 years. The problem of reducing the cultivated areas is associated not only with some of economic difficulties in the region in 1990 - 2000 but also with the degradation of the systems of irrigation canals and rivers due to an insufficiently developed system for regulating water consumption for agriculture.

The use of water for agricultural purposes both in the Don region and in the Russian Federation as a whole is characterized by a weak regulation system. The current regime for the exploitation of water resources is associated with a high anthropogenic load and low efficiency. It is noted [11] that the current state of the water system is caused by the influence of a number of factors:

- the use of obsolete technologies and equipment with a high level of consumption of water and energy resources, as well as the lack of systems for recycling water supply and purification of drainage waters coming from irrigated lands;

- irrational organization of the process of water supply and irrigation of irrigated lands associated with deviation from the optimal irrigation time, violation of its frequency, exceeding the recommended irrigation and irrigation norms, lack of necessary operational measures to clean irrigation canals, pipelines and drains;

- the imperfection of environmentally oriented regulatory and legal regulators of water resources use by enterprises of the reclamation complex; 
- low efficiency of the use of instruments of state support and stimulation of resource conservation in irrigated agriculture, as well as the secondary importance of their functioning within the framework of the general environmental policy of the state;

- the lack of payment for the use of water resources by the enterprises of the reclamation complex, which prevents the formation of market relationships between the subjects of agriculture and water management, as well as reduces the effectiveness of the use of economic instruments for regulating water use in irrigated agriculture.

The solution to the above problems is the transition to a system of paid water use. The introduction of a payment system should contribute to the modernization of the reclamation complex, with the introduction of resource-saving technologies. The consequence of the development of the water distribution system will be a decrease in the specific water intensity of agricultural production on irrigated lands [11].

It is known that in arid and semi-arid regions, an increase in anthropogenic pressure associated with population growth and an increase in the level of economic development requires more water resources, which inevitably leads to their depletion. The quality of water resources of the basin rivers of the Rostov region is determined by the flow of small rivers and canals. This determines the main environmental problems of the region. The high anthropogenic load on the small rivers of the region is associated with a high anthropogenic load. Water resources are used for drainage, irrigation and water supply in agriculture and fisheries. Livestock complexes, industrial enterprises, and irrigation systems pollute the rivers of the basin. Water quality is influenced by the unregulated washout of pollutants from urbanized and agricultural areas. The intense anthropogenic load led to such negative processes as siltation of channels, loss of drainage capacity by watercourses, floodplain swamping, rise in the level of groundwater, etc. Wastewater treatment is a problem. If the effluents of industrial enterprises and urban settlements are purified, then agricultural effluents are not purified and directly enter the rivers of the Don basin.

A technological approach to solving the problem of insufficient water supply is the development of systems for collecting and transporting water, often leading to an increase in the volume of water withdrawn. Such an extensive approach inevitably leads to negative consequences for aquatic ecosystems. For the water system of the Lower Don, where the volume of water withdrawal has already exceeded the critical point, a simple increase in the volume of water consumption will accelerate the processes of degradation of the water network.

At present, in the world practice of water resources management, there is an understanding that supply-side policy alone is not enough to meet the constantly growing demand. Proposed additional regulatory solutions on the demand side (e.g. charging, caps) to regulate demand and rebalance water basins [12]. It is believed that the implementation of such a water policy will limit the choice of users and induce adaptive responses with non-trivial consequences for the economy, especially in the agricultural sector [12]. The implications of user behavioural responses to policy on the demand side will go beyond the traditional sectoral approach and spread throughout the economy through forwarding and backward linkages between economic sectors.

The introduction of new mechanisms for regulating water consumption in agriculture requires a detailed economic analysis, consisting of an assessment of both microeconomic and macroeconomic indicators. The methods of microeconomic impact include assessing the reaction of consumers of the irrigation system, while macroeconomic impacts are expressed in general economic impact at the sectoral, regional and national levels [12, 13]. Ramiro Parrado et al. [13] performed a combined analysis of macro- and microeconomic analysis of the regulation of paid water consumption using the example of the Castile and León Region in Spain. The authors have shown that a reduction in water consumption can be achieved with less economic losses than expected in the framework of traditional stand- 
alone microeconomic models. It is assumed that the result of the introduction of payment for the reduction of production costs in irrigation agriculture will be a reorientation of the producer to water-intensive types of crops.

Modernization of the irrigation network can act as regulatory mechanisms to reduce the cost of paid irrigation. This approach will ultimately lead to the modernization of the irrigation canal system and the cleaning of small river channels in the region [14]. In world practice, offers several approaches to irrigate arid lands. The main such approaches include reduction of irrigation water losses during transportation to irrigated areas; the use of watersaving irrigation systems such as drip irrigation and micro-irrigation; irrigation scheduling using electronic plant and soil sensors and remote sensing models; incomplete irrigation; introduction of drought-resistant crops; application for irrigation of salt and wastewater [13].

The water irrigation system, due to its length, complexity and importance for the life of the whole region, requires initially large capital investments. For this reason, the participation of the state in the allocation of water resources is necessary, even in a market economy. In world practice, this regulatory function is often associated with the establishment of water charges. It is shown that setting prices for water is an effective way to improve the quality of water use through investments in irrigation technologies or return flow. It has been noted that a $20 \%$ increase in water prices can increase productivity by $43 \%[8,13]$.

\subsection{The possibility of introducing water tariffs payment}

When determining the amount of payment for the provided water supply service, only the volume of water supplied to the water consumption is taken into account. Taking into account the efficiency (efficiency) of the main and distribution channels of irrigation systems, when providing water supply services, all points of the water supply are equipped with water flow sensors. Within the boundaries of the activities of amelioration institutions and their branches, it is possible to use both one-rate (per cubic meter rate) and two-rate (per hectare and cubic meter rates) tariffs (presented in Figure 1).

Taking into account the probabilistic nature of changes in natural and climatic conditions and the stability of the economic activity of land reclamation and water management organizations involves the use of a two-rate system of payment for the use of water resources in the production of agricultural products on irrigated lands. The procedure for settlements at a one-rate tariff is recommended to be used in cases of providing water supply services in the area of operation of irrigation and watering systems, where the volume of water resources supplied to consumers is less dependent on natural and climatic conditions [11].

The one-rate tariff includes all costs payable by water consumers and charges by the current legislation. It is recommended to apply the procedure for settlements at a two-rate tariff in the area of operation of irrigation systems when providing services for the supply of water only for irrigating crops.

The two-part tariff includes two rates: the first-rate - per hectare - is formed at the expense of conditionally fixed costs, the size of which does not depend on the volume of water supply, the second rate - per cubic meter fee - is formed at the expense of conditionally variable costs, the amount of which depends on the amount supplied the volume of water at the point of delivery to an agricultural enterprise, as well as charges under applicable law.

The per hectare part includes the costs of operation and maintenance of irrigation systems payable by consumers: wages, daily allowances (during a business trip), payroll, communication services, maintenance, other work, depreciation, materials (fuels and 
lubricants, spare parts, etc. etc.), utilities, an increase in the cost of inventories, maintenance of pumping stations.

Water tariffs payment

\begin{tabular}{c}
\hline $\begin{array}{c}1 . \text { The one-rate tariff } \\
\text { includes all costs payable by } \\
\text { water consumers and charges }\end{array}$ \\
.
\end{tabular}

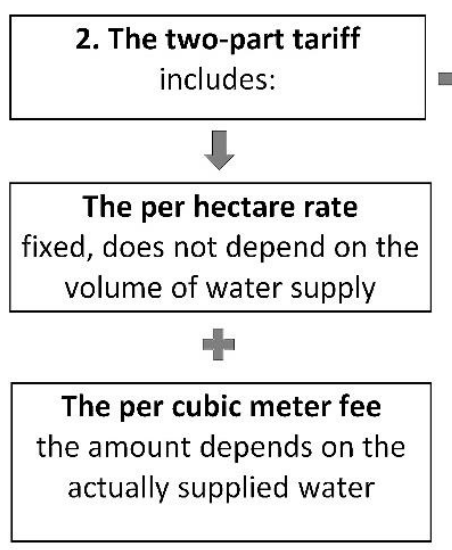

Features of tariffs

It is recommended if water
resources are only slightly
dependent on climatic
conditions

Accounting change in
climatic conditions and the
stability of economic
activity
It recommended using in
the area of irrigation
systems only for watering
crops

Fig. 1. Two types of water tariffs payment.

The per hectare rate is set for 1 hectare of irrigated area, provides reimbursement of the standard of conditionally fixed costs of melioration and water management organization and is collected from the water consumer regardless of the amount of water used by the agricultural enterprise. The cubic meter part includes the cost of electricity for head pumping stations of federal ownership (lifting and pumping stations), the cost of current repairs of electrical and hydromechanical equipment, and commissioning.

The per cubic meter rate is set for one cubic meter of water supplied to an agricultural enterprise, provides reimbursement of the standard of conditionally variable costs of a land reclamation and water management organization.

Some analysts rightly believe that the attitude towards the issue of payment for water only from the point of view of market mechanisms is not enough $[4,15,16]$. Indeed, to increase the efficiency of water use, a well-thought-out regulatory mechanism with the participation of the state is needed $[17,18]$.

The results of the analysis of domestic and foreign experience in conducting paid water use in agriculture indicate the following:

- the system of paid water use in agriculture is an effective means of ensuring the rational use of water and other types of resources;

- the basis for determining the payment for water is the principle of cost recovery for construction, operation and maintenance of irrigation systems;

- development of paid water use is supported by the state.

Practically in all countries of the world, agricultural producers cover only part of the costs of operation and maintenance of the off-farm part of irrigation systems through payment for water, and the rest of the costs of water organizations are financed by the state. The move towards full cost recovery is gradual and relies on the ability of the agricultural producer to pay for water, i.e. the amount of payment for water depends on the profitability of agricultural production on irrigated land. 


\section{Conclusion}

In conclusion, we can say that the introduction of paid water use both in Russia and in foreign countries is aimed at increasing the responsibility of water users for the economical and efficient use of water resources and partial coverage of the costs of state water organizations for the operation of irrigation systems.

\section{References}

1. V. Bjornlund, H. Bjornlund, Agricultural Water Management 213, 454-467 (2019) doi:10.1016/j.agwat.2018.10.037

2. C.R. Jensen, J.E. Ørum, S.M. Pedersen et al., Journal of Agronomy and Crop Science 200(5), 333-343 (2014) doi:10.1111/jac.12067

3. C.D. Perez-Blanco, G. Delacamara, C.M. Gomez, Environmental Modelling \& Software 69, 90-100 (2015) doi:10.1016/j.envsoft.2015.03.006

4. B. Davidson, P. Hellegers, R.E. Namara, Current Opinion in Environmental Sustainability 40, 1-6 (2019) doi:10.1016/j.cosust.2019.06.001

5. M.V. Bolgov, A.I. Belyaev, A.M. Pugacheva, M.V. Vlasenko, M.V. Shulgin, Water Resources, 47(6), 1065-1076 (2020) doi:10.1134/S0097807820060032

6. A.P. Demin, Water Resources 47(6), 1077-1087 doi:10.1134/S0097807820060044

7. M.V. Bolgov, L.K. Levit-Gurevich, Water Resources 40(5), 544-553 (2013) doi:10.1134/S0097807813050023

8. G.G. Matishov, A.V. Kleschenkov, N.I. Bulysheva, K.V. Kreneva, V.L. Semin, G. Yu Glushchenko, Scientific problems of rehabilitation of Russian rivers and ways of their solution (2019)

9. R.G. Dzhamalov, M.B. Kireeva, A.E. Kosolapov, N.L. Frolova, Water resources of the Don basin and their ecological conditions (2017)

10. A.I. Sukhinov, A.E. Chistyakov, A.V. Nikitina, A.A. Filina, T.V. Lyashchenko, V.N. Litvinov, International Conference on Parallel Computational Technologies, 225-241 (2019) doi:10.1007/978-3-030-28163-2_16

11. S.M. Vasiliev, A.V. Akopyan, M.V. Vlasov, N.I. Safarova, Domestic and foreign experience in conducting paid water use in agriculture (2012)

12. R. Parrado, C.D. Pérez-Blanco, C. Gutiérrez-Martín, L. Gil-García, Science of The Total Environment 742, 140526 (2020) doi:10.1016/j.scitotenv.2020.140526

13. T. Hasegawa, S. Fujimori, T. Masui, Y. Matsuoka, Journal of cleaner production 114, 233-242 (2016) doi:10.1016/j.jclepro.2015.03.093

14. J.M. Tarjuelo, J.A. Rodriguez-Diaz, R. Abadía, E. Camacho, C. Rocamora, M.A. Moreno, Agricultural Water Management 162, 67-77 (2015) doi:10.1016/j.agwat.2015.08.009

15. M. Rath, M.G. Morgan, Progress in Nuclear Energy 122, 103269 (2020) doi:10.1016/j.pnucene.2020.103269

16. M. Strokal, H. Biemans, P. van Oel, Current Opinion in Environmental Sustainability 40, A1-A4 (2019) doi:10.1016/j.cosust.2019.11.007

17. N. Djanibekov, I. Bobojonov, U. Djanibekov, Cotton, Water, Salts and Soums, 389411 (2012) doi:10.1007/978-94-007-1963-7_23 
18. M. Aleksandrova, J.P. Lamers, C. Martius, B. Tischbein, Environmental Science \& Policy 41, 77-88 (2014) doi:10.1016/j.envsci.2014.03.001 